\title{
The year public health lost its soul
}

\author{
Damien Contandriopoulos ${ }^{1}$ \\ ${ }^{1}$ Affiliation not available
}

September 24, 2021

\begin{abstract}
The COVID pandemic was an acute test of public health capacities worldwide. Many will hail the successes obtained and stress the importance of the discipline. On the contrary, this commentary defends the idea that the COVID pandemic response forced public health to enter in a Faustian bargain with governments and realpolitik that threaten the very core of the discipline's principles.
\end{abstract}

\section{Introduction}

The COVID pandemic is, at many levels, an historical turning point and, for some, the poster-child illustration of the usefulness and centrality of public health. My own understanding is radically different, and I contend that the pandemic pushed the field of public health in a Faustian bargain where it reneged its core principles in a way that will have long lasting implications.

\section{The "Soul" of Public Health}

Public health, as a discipline, rests on three basic tenets. First, its goal of fostering individual and collective health and well-being implies benevolence. Second, interventions ought to rest on principles tested through scientific approaches. Finally, as the discipline evolved during the 20th century, equity became its third core pillar: Interventions should aim at reducing health disparities between individuals and between groups. Over time, the discipline also developed a tendency to debate how many angels can dance on the head of a pin, so any simple definition could certainly be discussed and debated. Nevertheless, few would contest that being equity driven, evidence-based, and benevolent are central to the very nature of public health.

However, public health isn't only a scientific discipline, it also is an applied practice, mostly taking place through specialized state bureaucracies. From national public health agencies to regional or local public health units, public health is firmly embedded in the state administrative apparatus. This operationalization of public health as a function of the state always had to contend with specific challenges related to its relations with governments and politics. Especially since, given the existing evidence on the social determinants of health, taken seriously, few goals would be as politically disruptive and subversive than trying to reduce health disparities. State-run public health bureaucracies therefore always had to carefully thread the line between their disciplinary ambitions and the political acceptability of their interventions. The resulting modus vivendi varied between jurisdictions but generally didn't involve renouncing to the core tenets described above as much as being selective in their translation into practices and recommendations. As a side note, it is plausible that public health disciplinary fondness for intensely scholastic debates around equity and evidence-based policy stems, in part, from the double-bind its applied arm must contend with 


\section{And then came COVID...}

Over the past decades, many events, from communicable diseases like HIV and Ebola to noncommunicable epidemics such as tobacco and opioid-related deaths, challenged the connection between public health disciplinary tenets and it's applied arm constraints. But none of these challenges came close to the disconnects that COVID brought.

Early 2020, public health state bureaucracies everywhere suddenly found themselves working hand-in-hand with governments to draft unprecedented emergency measures to control COVID transmission. Over the following year, this emergency period slowly turned into odd symbiotic relations between political powers and public health structures.

Most jurisdictions in Western countries adopted "balanced-containment" strategies regarding COVID. This approach is characterized by the ambition to balance, on the one hand, the number of coronavirus infections, hospitalizations and deaths and, on the other hand, the economic and social disruptions caused by strict infection control measures such as lockdowns (Oliu-Barton et al., 2021). The balanced-containment approach is different from the COVID-zero or elimination approach adopted by Atlantic provinces, New Zealand, China, and others. It is also different from the necrophiliac laissez-faire tried in Brazil and some US states.

Initial infection control measures implemented at the onset of the pandemic were drafted in the absence of strong evidence on transmission routes for the new coronavirus. For historical reasons (Molteni, 2021) the emphasis was on fomite and respiratory droplets. However, this focus ended up being misguided. By the summer of 2020, it became clear that the virus was likely airborne and by early 2021 the scientific consensus was that most COVID cases were caused by aerosol transmission (Allen \& Ibrahim, 2021; Tang, Marr, Li, \& Dancer, 2021). However, it also soon became clear that most Western state-run public health bureaucracies - as well as international public health bodies such as the WHO - actively defended erroneous initial theories on COVID transmission long after it was rational to do so. Instead of working toward the development and communication of evidence-based COVID prevention strategies, public health institutions found themselves stonewalling and actively contradicting scientific developments in the field (Greenhalgh, Ozbilgin, \& Contandriopoulos, 2021).

Over the same period, the focus of containment strategies shifted. Economic actors impacted by lockdowns and infection control measures successfully convinced many governments to slowly push the balance of the containment strategies toward looser infection control measures and the acceptance of higher infection rates. The reference point of balanced-containment strategies slowly shifted from minimizing cases to optimizing intensive care bed occupancy rates near or above $100 \%$. The combination of outdated and misguided infection prevention advice and looser restrictions contributed to fuel higher and higher waves of cases.

In the meantime - and unsurprisingly - the balanced-containment strategies were also shown to be deeply inequitable. Both the incidence and relative risk of death from COVID were highly correlated with income, social status and racialized status (Karmakar, Lantz, \& Tipirneni, 2021). The likely reason being that people in high incidence groups were also the ones whose work could not be done remotely, being exposed to highrisk occupations (Middleton, Reintjes, \& Lopes, 2020), living in higher density tenements, and not having much of a choice in those matters. The weaker infection control measures were, and the further they were pushed toward the maximization of economic activity, the worse the impact on equity.

By early summer 2021, some jurisdictions - such as Western Canada, the UK, many US states - decreed that the pandemic was over and that preventions measures weren't needed anymore. Those decisions, explicitly endorsed and defended by public health officials, were announced while international evidence on the transmissibility and immune evasion capacity of the Delta variant showed that vaccination alone would not prevent further waves of infection. Like clockwork, those "reopening" plans (Bell, 2021; Lafontaine, 2021; Wyton, 2021) paved the way to a brutal $4^{\text {th }}$ wave. A situation made worst by the fact prevention advice remained anchored in debunked theories about droplets and that few (if any) effective prevention measures - such as improved ventilation of indoor public spaces, advice on good masking techniques, limits on large 
indoor gatherings, etc.- were implemented.

\section{The Faustian Bargain [1]}

In most Western countries, and in the majority of Canadian provinces, the COVID response symbiotically produced by political actors and public health institutions caused multiple disconnects: between the scientific evidence on COVID transmission and the public health sanctioned advice; between public health and governmental discourses prioritizing the wellbeing of the population and containment strategies focused mostly on economic indicators; and between inclusive discourses putting forward collective sacrifices for a common good and deeply inequitable interventions.

At the time of writing this commentary, those disconnects have grown too deep to be hidden. More efforts seem to go in controlling the political spin and rationing the information made available than in trying to correct documented deficiencies (Daflos, 2021; Thomas \& Gervais, 2021). This is not to say that there is no push back by some public health officials and it could be that fierce debates are taking place behind closed doors. But, in most jurisdictions there have been little to no place for open dissension (Deep Singh, 2021).

Somewhere in the last year public health lost its soul. The goal of fostering individual and collective health and well-being became secondary to disputable economic growth indicators and radical utilitarianism regarding the value of human lives. The focus on equity that was central in all public health discourses fell as one of the first victims of the discipline turn toward political symbiosis and realpolitik. The ambition to be a science-driven evidence-based practice continues to be daily trampled in evidence-free statements (Daflos, 2021; Goldman, 2020).

In the following months and years, we should expect the COVID pandemic to be used to support calls for increased budgets by public health state bureaucracies. And many valid arguments can be made in support of stronger public health. However, it would be a huge mistake to ignore what the discipline lost in the pandemic, and the causes explaining the disconnects discussed here. The pandemic caused public health to turn back to its medical roots instead of leveraging the interdisciplinarity it long preached (Greenhalgh et al., 2021). It pushed many public health state bureaucracies to become tools for governments instead of being carriers for evidence-based information. And more generally it caused the discipline to renege most of its principles.

\section{References:}

Allen, J. G., \& Ibrahim, A. M. (2021). Indoor Air Changes and Potential Implications for SARS-CoV-2 Transmission. JAMA, 325(20), 2112-2113. doi:10.1001/jama.2021.5053

Bell, R. (2021, Sept 14, 2021). Kenney's Best Summer Ever to Worst ICU Numbers Ever. Calgary Sun. Retrieved from https://calgarysun.com/opinion/columnists/bell-kenneys-best-summer-ever-toworst-icu-numbers-ever

Daflos, P. (2021). Reduced contact tracing, child vaccination debate revealed to B.C. doctors as province pushes return to normal. CTV News Vancouver. Retrieved from https://bc.ctvnews.ca/reducedcontact-tracing-child-vaccination-debate-revealed-to-b-c-doctors-as-province-pushesreturn-to-normal-1.5586795

Deep Singh, K. (2021, Sept. 14, 2021). As India's Lethal Covid Wave Neared, Politics Overrode Science. The New York Times. Retrieved from https://www.nytimes.com/2021/09/14/world/asia/indiamodi-science-icmr.html?smtyp=cur\&smid=tw-nytimes

Goldman, E. (2020). Exaggerated risk of transmission of COVID-19 by fomites. The Lancet Infectious Diseases, 20(8), 892-893. doi:10.1016/S1473-3099(20)30561-2 
Greenhalgh, T., Ozbilgin, M., \& Contandriopoulos, D. (2021). Orthodoxy, illusio, and playing the scientific game: a Bourdieusian analysis of infection control science in the COVID-19 pandemic. Wellcome Open Research, 6(126). doi:10.12688/wellcomeopenres.16855.1

Karmakar, M., Lantz, P. M., \& Tipirneni, R. (2021). Association of Social and Demographic Factors With COVID-19 Incidence and Death Rates in the US. JAMA Network Open, 4(1), e2036462-e2036462. doi:10.1001/jamanetworkopen.2020.36462

Lafontaine, A. (2021, Sept. 17, 2021). mer of hubris has led Canada's health systems to the verge of collapse. The Globe and Mail. Retrieved from https://www.theglobeandmail.com/opinion/article-asummer-of-hubris-has-led-canadas-health-systems-to-the-verge-of/?

Middleton, J., Reintjes, R., \& Lopes, H. (2020). Meat plants - a new front line in the covid-19 pandemic. BMJ, 370, m2716. doi:10.1136/bmj.m2716

Molteni, M. (2021). The 60-Year-Old Scientific Screwup That Helped Covid Kill. Wired, May 13, 2021. Retrieved from https://www.wired.com/story/the-teeny-tiny-scientific-screwup-thathelped-covid-kill/

Oliu-Barton, M., Pradelski, B. S. R., Aghion, P., Artus, P., Kickbusch, I., Lazarus, J. V., . . . Vanderslott, S. (2021). SARS-CoV-2 elimination, not mitigation, creates best outcomes for health, the economy, and civil liberties. The Lancet, Online first. doi:10.1016/S0140-6736(21)00978-8

Tang, J. W., Marr, L. C., Li, Y., \& Dancer, S. J. (2021). Covid-19 has redefined airborne transmission. BMJ, 373.

Thomas, B., \& Gervais, B. (2021, Sept 14th 2021). Hinshaw believes 'Open for Summer' plan led to current spike in COVID cases. Calgary Herald. Retrieved from https://calgaryherald.com/news/localnews/hinshaw-believes-open-for-summer-plan-led-to-current-spike-in-covid-cases

Wyton, M. (2021, Aug. 5th 2021). BC to Stay the Course on Reopening Plan Despite Rise in Cases. The Tyee. Retrieved from https://thetyee.ca/News/2021/08/05/BC-Stay-Course-Reopening-Plan/

[1] The term "Faustian bargain" implies sacrificing one's values for power or material gain. It comes from a middle age legend about Johann Georg Faust, a German Alchemist who allegedly sold his soul to the devil in exchange for infinite knowledge and pleasures.

\section{Declaration:}

-Conflict of Interest: The author declares to have no conflicts of interest to report.

-Funding Statement: This work did not receive any funding

-Author's Contribution: I wrote the commentary as a sole author. However, I want to thank Trish Greenhalgh and Mustafa Ozbilgin who provided numerous insights during informal discussions

-Availability of data and material: All material used is in the public domain

-Code availability: n/a

-Ethics approval: This commentary did not use data that require ethical approval

-Consent to participate : n/a

-Consent for publication $\mathrm{n} / \mathrm{a}$ 